\title{
Measurements of water use by prairie grasses with heat balance sap flow gauges
}

\author{
R.S. SENOCK AND J.M. HAM
}

\begin{abstract}
Authors are post-doctoral fellow, Department of Agronomy and Soil Science, University of Hawaii, 1910 East West Rd, Honolulu 96822, and associate professor, Department of Agronomy, Kansas State University, Manhattan 66506-3801. At the time of the research Senock was a graduate research assistant in the Evapotranspiration Laboratory at Kansas State University.
\end{abstract}

\begin{abstract}
Direct and continuous measurements of water use by range grasses are needed by both range scientists and land managers. This study tested a heat balance sap flow gauge on individual culms of the tallgrass prairie species big bluestem (Andropogon gerardii Vitman) and indiangrass [Sorghastrum nutans (L.) Nash]. Gauge performance was evaluated on potted plants in the laboratory, greenhouse, and field by comparing sap flow to gravimetric measurements of transpiration. In the laboratory, gauge-measured water loss was consistently within $\pm 10 \%$ of gravimetric measurements for both species at flow rates $\leq 4 \mathrm{~g}$ hour ${ }^{-1}$. The first-order time constant of the gauge was calculated to be $<20$ seconds. In the greenhouse, sap flow estimates were consistently below gravimetric water loss and negative flows were often computed because of suspected errors in the radial heat flux component. Laboratory data showed that despite the gauge being surrounded with insulation, errors in the heat balance could occur because of external air temperature changes. In the field, environmental alterations in the stem energy balance affected the accuracy of gauges placed outside a plant canopy, but accurate measurements did occur when the plants were placed within a plant canopy. Heat transfer analysis indicated that foam insulation should be 20 to $25 \mathrm{~mm}$ thick to minimize the effect of the environment on gauge performance.
\end{abstract}

Key Words: big bluestem, indiangrass, energy balance, heat flux

The central role of plant- and soil-water relations in rangeland ecosystems has long been recognized by both scientists and land managers (Brown 1977). Forage plant breeders often evaluate plant water use in response to drought as a criterion in species selection programs (Johnson and Asay 1993), and removal of woody species often is prescribed by land managers to enhance soil water availability for grass species (Griffin and McCarl 1989). However, commonly used methods of measuring or estimating range-plant water use, such as porometers (Ansley et al. 1991), lysimeters (Parton et al. 1981, Wight and Hanson 1990), or evapotranspiration models (Massman 1992, Stannard 1993) do not provide information on transpiration from whole plants. Only with the recent development of sap flow gauge technology has

Contribution No. 94-167-J from the Kansas Agricultural Experiment Station, Manhattan, KS. The authors express appreciation to Dr. Byron W. Jones, Dep. of Mechanical Engineering, KSU, and Dr. Gourish Sirdeshpande, senior research scientist, Armstrong World Industries for suggestions on the heat transfer analysis. Manuscript accepted 24 Jul. 1994. water use by a rangeland shrub been measured directly and continuously under field conditions (Dugas and Mayeux 1991, Dugas et al. 1992).

In general, the use of sap flow gauges has been almost entirely restricted to large dicots (Fichtner and Schulze 1990, Ham and Heilman 1991, Steinberg et al. 1991, Groot and King 1992). Far fewer studies have been reported using sap flow gauges on grass species, and these have been limited to larger agronomic species like corn (Zea mays L.) (Gavloski et al. 1992). Only Sakuratani $(1979,1990)$ has reported sap flow measurements on a small cereal, rice (Oryza sativa L.), but the gauge used was not removable and had to be built directly on the plant stem. No studies document the use of sap flow gauges on rangeland grass species. A removable sap flow gauge has been designed that can accommodate the small diameter and often irregular shaped stems of native grasses (Senock and Ham 1993). The objective of this study was to test and validate this new gauge design for use on prairie grasses and assess the utility or value of this gauge for use on rangelands.

\section{Materials and Methods}

Sap flow gauges used in the study had the same basic components described by Baker and van Bavel (1987), which included a thin-film electrical resistance heater, 2 thermojunctions (copperconstantan) each located above and below the heater, a 10 -junction thermopile, and cork-neoprene gasket material to which the components are attached (Fig. 1a). Details on the design of the major components for a gauge configuration adapted for small plant stems can be found in Senock and Ham (1993). The gauge surrounds a small portion of plant stem (Fig. 1b), is covered with foam insulation and is held in place with plastic clips (Fig. 1c). The gauges are connected to a datalogger to record the analog voltage outputs.

Use of the gauges to measure sap flow is based on the steady state energy balance of a heated portion of plant stem defined as

$$
Q=Q_{r}+Q_{v}+Q_{f}+S
$$

where each component is a heat flux (watts, W) calculated from appropriate equations describing heat flow within the system. Indepth discussions regarding gauge theory and the mathematical equations involved are provided by Sakuratani $(1979,1981)$. For clarity in the discussion of the results from this study, the equations for each heat flux will be briefly presented. 
(A)

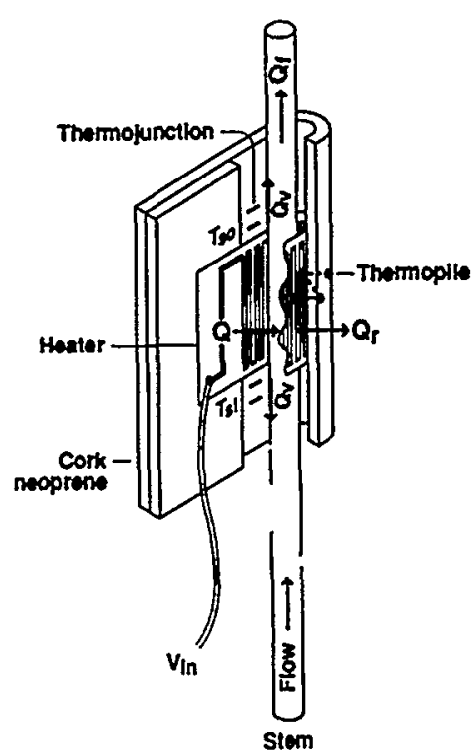

(B)

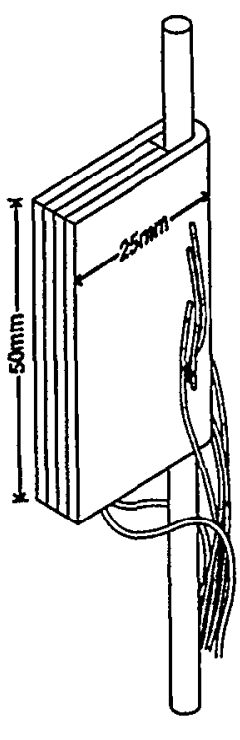

(C)

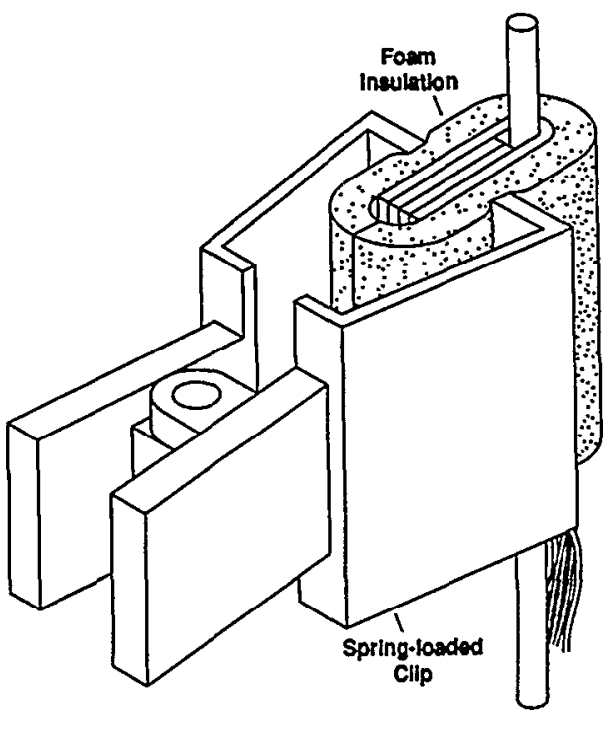

Fig. 1. Schematic diagram of the sap flow gauge used in the study. Multiple views depict: (A) gauge components and associated heat fluxes, $Q$ $=$ power input, $Q_{f}=$ convective heat flux, $Q_{r}=$ radial heat flux, $Q_{\nu}=$ axial heat flux, and $T_{s o}-T_{s i}=$ system temperature; (B) the U-shaped configuration when in place on the plant stem; (C) gauge appearance on the plant stem when covered with foam insulation and secured with a spring-loaded plastic clip.

The total power, $Q$, is applied to the stem segment by the thinfilm heater (Fig. 1a) and is calculated from the input voltage $(V)$ and the resistance $(R)$ of the heater $\left(Q=V^{2} / R\right)$. For grasses with small stem diameters, $V$ ranges from $1.0-2.0$ volts, $R$ ranges from 45-50 ohms, and $Q$ ranges from $0.02-0.08$ Watts. The radial heat flux, $Q_{r}$ is the product of the radial temperature gradient $(E)$ as measured with the thermopile (Fig. la) and the thermal conductivity $\left(K_{g}\right)$ of the gauge $\left(Q_{r}=K_{g} \cdot E\right)$. Values of $K_{g}$ typically range from 0.3-0.7 Watts $/ \mathrm{V}$ and can be estimated from data during periods of minimal flow such as during the predawn hours (Steinberg et al. 1989, Senock and Ham 1993). The axial heat flux, $Q_{v}$, is determined from the stem thermal conductivity $\left(K_{s t}\right)$, the cross-sectional area of the stem $(A)$, and the temperature gradient up and down $(\Delta T / \Delta X)$ the stem surface $\left(Q_{v}=K_{s t} \bullet A \cdot\right.$ $(\Delta T / \Delta X)$ ). Typical values of $K_{s t}$ are in the range $0.40-0.60$ Watts $\mathrm{m}^{-1} \mathrm{~K}^{-1}$ which Sakuratani (1984) calculated from the sum total of the products of conductivity for cellulose, water, and air and their fractional volumes in the plant stem. The variable $A$ represents the stem cross-sectional area $\left(\mathrm{m}^{2}\right)$ that can conduct heat, which would include epidermal, cortex, and vascular tissues. For many range grasses, the lower portion of culm that is surrounded by the gauge will be either hollow or semisolid (Gould and Shaw 1983). In determining the appropriate $A$ for the equation, the central hollow area can simply be subtracted from the total stem area. The degree of error in estimated sap flow introduced by an error in $A$ is minimal, because $Q_{v}$ is a minor portion $(<10 \%)$ of the total energy balance (Sakuratani 1981). The $\Delta T$ is the difference in stem surface temperature $(K)$ among the 4 thermojunctions located above and below the heater, and $\Delta X$ is the distance $(3-5 \mathrm{~mm})$ between 2 thermojunctions within a pair (Fig. 1a). The thermojunctions can be wired in either a differential or absolute mode if the datalogger used can produce an actual temperature $\left({ }^{\circ} \mathrm{C}\right)$ from the analog signal inputs. The differential scheme reduces the required number of datalogger input channels (Steinberg et al. 1989). The term $S$ in equation 1 represents the rate change in heat storage within the stem. However, empirical data have shown that including this term has minimal effect on diurnal sap flow calculations (Dugas 1990) because it is typically $\leq 3 \%$ of the stem energy balance (Senock and Ham 1993), and thus it can usually be ignored when measuring sap flow for plants with small stems.

For calculating sap flow, equation 1 is rearranged as

$$
\mathrm{F}=\frac{Q-Q_{r}-Q_{v}}{C\left(T_{s o}-T_{x i}\right)}=\frac{Q_{\mathrm{f}}}{C\left(T_{s o}-T_{s i}\right)}
$$

where $F$ is the sap flow rate $\left(\mathrm{kg} \mathrm{s}^{-1}\right), Q_{f}$ is the residual heat flux, $C$ is the heat capacity of the sap $\left(4187 \mathrm{~J} \mathrm{~kg}^{-1} \mathrm{~K}^{-1}\right)$, and $T_{s o}-T_{s i}$ represents the difference in temperature of the sap flowing into and out of the heated stem segment as estimated from the stem surface temperatures measured with the paired thermojunctions (Fig. 1a).

\section{Test Procedures}

Plant species used in the study were big bluestem (Andropogon gerardii Vitman) and indiangrass [Sorghastrum nutans (L.) Nash] grown in the greenhouse from seed obtained from the USDA/SCS Manhattan Plant Materials Research Center in Kansas. Plants were grown in 0.25 liter plastic pots filled with a $50 \%$ by volume mixture of fritted clay and a commercial potting soil. Because the plants had several culms, all but 1 plant culm was removed, and the gauges were attached at the base of the culm, immediately above the soil surface and beneath all leaves and leaf sheaths. Stem diameters were $\leq 5 \mathrm{~mm}$, and stem radial geometries were clliptical. Gauge heater width was $10 \mathrm{~mm}$ and lengths were 10 or $15 \mathrm{~mm}$ (Heater Designs, Bloomington, Calif.) depending on stem size. During testing, gauges were surrounded with foam insulation ( 7 to $12 \mathrm{~mm}$ thickness), held in place with plastic clips, and shielded from radiation with aluminum foil. 
Performance tests were conducted in the laboratory from July to August, 1991, under 2 high pressure sodium lamps (Model LU400, Energy Technics, York, Penn.) with maximum irradiance at the top of the plant near 225 Watts $\mathrm{m}^{-2}$ (pyranometer Model 848, Eppley Laboratory, Newport, R.I.). The lights were timed independently to produce different light intensity regimes and obtain various levels of transpiration. Tests were conducted from August to October, 1991, in a whitewashed greenhouse with evaporative cooling. Thermocouples were wired in the absolute mode to give actual measurements of stem surface temperatures with gauge signals sampled every 15 seconds and stored as 30 minute averages with a data logger (Model 21X, Campbell Scientific Ltd., Logan Ut.). Measured sap flow rates were compared with concurrent gravimetric estimates of water loss as measured by an electronic balance ( $0.01 \mathrm{~g}$ resolution) every $30 \mathrm{~min}$ utes.

To better examine the effects of external environmental conditions on gauge performance, an artificial flow system similar to the design of Sakuratani (1979) was built in the laboratory. Briefly, the main components were arranged in the order of a constant-pressure water delivery system, a $15 \mathrm{~cm}$ section of a senesced, hollow indiangrass flowering culm ( $5 \mathrm{~mm}$ diameter), and a $5 \mathrm{~mm}$ diameter glass extension tube at the distal end of the culm. Water flowed through the culm and into a covered catchment beaker placed on an electronic balance. The flow rate was monitored every 30 seconds with gravimetric measurements of the system outflow. The system was arranged horizontally, and a sap flow gauge with $7 \mathrm{~mm}$ thick insulation was attached and operated as in all performance tests. The surface temperature of the gauge insulation was raised with a heat gun and lowered with Freon to mimic sudden changes in air temperature. Gauge surface temperature was measured with a thermacouple placed on the insulation surface beneath the $\mathrm{Al}$ foil shield.

Field tests were conducted at Kansas State University's Ashland Research Farm during June and July, 1992. On each test day, 2 potted plants of each species were placed within a full canopy of mature oats (Avena sativa L.) and 2 in an adjacent open area. Thermocouples were wired in the differential mode. Daily estimates of total sap flow were compared with beginningand end-of-day gravimetric weights. Global irradiance and air temperature within and outside the canopy also were measured. Gauge signals and environmental factors were sampled every 15 seconds with a data logger/multiplexer arrangement (Models 21X/AM416, Campbell Scientific Ltd., Logan, Ut.) and stored as 20 minute averages. Gauge insulation thickness was $12 \mathrm{~mm}$. Prior to all tests, pots were well watered and allowed to drain before being sealed in plastic bags to minimize soil evaporation. Pots also were covered with aluminum foil to minimize radiation effects on soil temperature.

\section{Results and Discussion}

\section{Laboratory Tests}

Repeated tests on both species showed the gauges were consistently accurate within $\pm 10 \%$ of the gravimetric measurements. For the specific examples presented in Figure 2, cumulative water loss measured with the gauge was within $+7 \%$ for big bluestem and $-3 \%$ for indiangrass. This degree of accuracy is equivalent to that reported for several herbaceous and woody dicots, despite maximum flow rates $\leq 4 \mathrm{~g}$ hour' ${ }^{-1}$ Such low maximum flow rates are one-tenth of commonly reported values $\left(>50 \mathrm{~g} \mathrm{hour}^{-1}\right)$ for larger crop species (Sakuratani 1987, Dugas 1990, Ham and Heilman 1990). Sakuratani $(1979,1990)$ also reported estimates within $\pm 10 \%$ for rice plants when flows were $>5 \mathrm{~g}$ hour ${ }^{-1}$ but accuracy apparently decreased at lower flow rates because of poor gauge sensor response time and stem anatomy (Sakuratani 1990). The high degree of accuracy in this study can be attributed to the correct partitioning of the heat energy flux components and the dynamic response of the gauge to sudden changes in sap flow.

When partitioning the heat flux components, $Q_{r}$ and $\mathrm{Q}_{\mathrm{V}}$ are obtained from direct sensor measurements, whereas $Q_{f}$ is calculated as a residual (eq. 2). Because sap flow is directly proportional to $Q_{f}$, any heat flux not properly attributed to $Q_{r}$ or $Q_{v}$, will result in an inaccurate estimate of $Q_{f}$ and thus sap flow. With $Q_{v}$ typically $<10 \%$ of $Q$ (Sakuratani 1981, Ham and Heilman 1990), the measurement of $Q_{r}$ then becomes the major source of potential error in estimating sap flow at low flow rates (Senock and Ham 1993). During high flows, convective heat transport in the sap stream causes $Q_{f}$ to be the dominant flux component, whereas during periods of low flow, $Q_{r}$ is the dominant flux component. In general, a wide fluctuation typically occurs in $Q_{f}$ as flows increase ( $>20 \mathrm{~g}$ hour $\left.^{-1}\right)$ and the fractional proportion of $Q_{r}(<0.20$ of $Q$ ) becomes small (Steinberg et al. 1989, Dugas 1990, Ham and Heilman 1990, van Bavel 1991, Senock and Ham 1993). In contrast, for the grasses in this study, only small variations occurred in all the heat flux components, and the fractional proportion of $Q_{r}$ remained above 0.70 regardless of flow rate (Fig. 2b). For most range grasses, sap flows will probably be $<20 \mathrm{~g}$ hour ${ }^{-1}, Q_{f}$ will be a minor portion of the total heat flux and $Q_{r}$ will always dominate the heat loss components. The measurement of $Q_{r}$ will thus be critical to accurately estimating sap flow of range grasses. As previously stated, however, $Q_{r}$ is directly proportional to the radial temperature gradient and the thermal conductivity $\left(K_{g}\right)$ of the gauge, with the later typically measured during a period of minimal sap flow. For each laboratory test, the value of $K_{g}$ used in calculating $Q_{r}$ was determined during the low flow period just prior to turning on the lights. Given the accuracy between the measured gravimetric and computed sap flow rates in the laboratory tests (Fig. 2), both $K_{g}$ and the radial temperature gradient were probably measured accurately, which resulted in an accurate accounting of the heat flux components.

In addition to partitioning correctly the heat flux components, the other important variable in calculating sap flow is $T_{s o}-T_{s i}$. This parameter is measured from the temperature sensors on the stem surface. The stem surface temperature is then assumed to be representative of the sap temperature in the radial cross-sectional (Sakuratani 1981). For the assumption to be true, thermal equilibrium has to be achieved between the exterior stem surface and the sap. According to the simulation study of Baker and Nieber (1989), this assumption is violated in the case of monocots because of the scattered arrangement of the vascular tissue within the stem. However, thermal equilibrium is not only dependent on stem anatomy but also on sap velocity and stem size. At high sap velocities thermal equilibrium may not be reached because of the rapid convective heat loss in the moving sap stream (Baker and Nieber 1989). At high flow rates, enlarging gauge heater width as stem diameter increases may be a solution to reducing stem temperature gradients and improving thermal equilibrium (Ham and Heilman, 1990). Using an estimate of the hydroactive xylem conducting area in a stem of $5 \mathrm{~mm}$ diameter $\left(5 \mathrm{~mm}^{2}\right)$ and the maxi- 

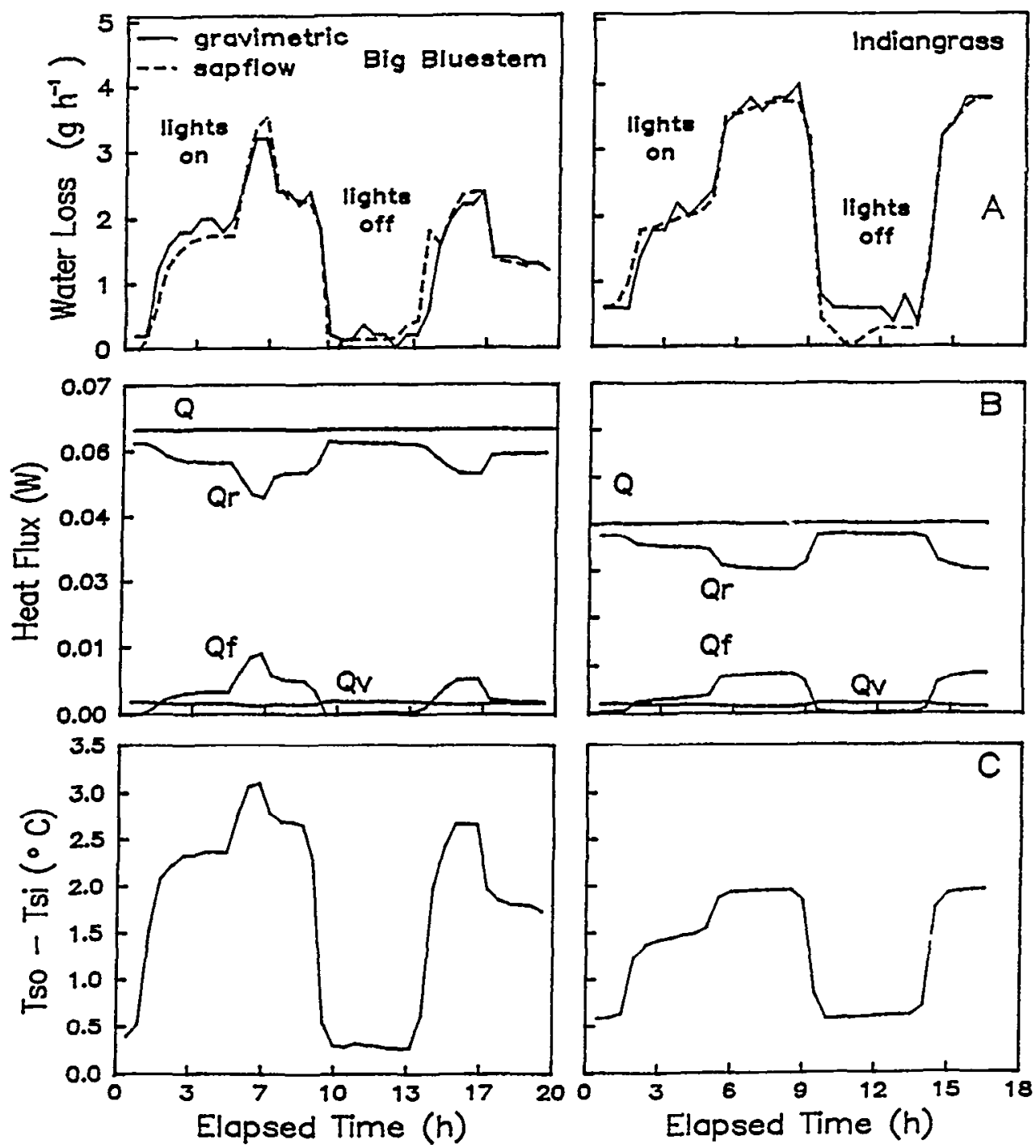

Fig. 2. Representative laboratory examples of the performance of a sap flow gauge on individual culms of big bluestem and indiangrass: (A) gauge computed sap flow compared to gravimetric measurements of plant water loss; (B) heat balance components, $Q=$ power input, $Q_{f}=$ convective heat flux, $Q_{r}=$ radial heat flux, $Q_{v}=$ axial heat flux, and (C) $T_{s o}-T_{s i}$.

mum flows of $4 \mathrm{~g}$ hour-1 recorded in the laboratory tests the computed sap velocities would be $\leq 0.2 \mathrm{~mm} \mathrm{sec}^{-1}$. This is much less than the $0.55 \mathrm{~mm} \mathrm{sec}^{-1}$ computed for corn plants with flow rates near $100 \mathrm{~g} \mathrm{hour}^{-1}$ when sap flow was underestimated because of non-equilibrium temperatures (Cohen et al. 1993). Furthermore, as recommended by Sakuratani (1981), the ratio of the gauge heater width $(10 \mathrm{~mm})$ to stem diameter $(\leq 5 \mathrm{~mm})$ was $2: 1$. Thus, it is unlikely that large interior cross-sectional temperature gradients could exist, and the assumption that radial temperature can be estimated from measurements at the surface is probably valid for the small stems that would typify most range grasses. The accuracy of the sap flow estimates in the laboratory tests for both species indicate that $T_{s o}-T_{s i}$ was probably estimated correctly by the sensors on the stem surface.

The nearly identical response of $T_{s o}-T_{s i}$ to abrupt changes in sap flow (Fig. 2c) was in contrast to the typical relationship expected when using thermal tracer techniques for measuring the flow of fluids in contained volumes (such as pipe or stems). Theory dictates that as flow increases from zero, $T_{s o}-T_{s i}$ initially increases very rapidly to a maximum and then begins to decrease as flow rates continue increasing. This response pattern is due to a distortion of the isothermal field in the direction of flow (Baker and Nieber 1989). For both species, $T_{s o}-T_{s i}$ increased as flow increased (Fig. 3), indicating that flows were in a range such that $T_{s o}-T_{s i}$ had not been maximized and the change in $T_{s o}-T_{s i}$ as flow rate changed $\left(\partial T_{s o}-T_{s i} / \partial F\right)$ was greater than 0 . The large value of $\partial T_{s o}-T_{s i} / \partial F$ at low flows is one of the key reasons why accurate measurements of sap flow are possible in small stems even when fluctuations in the heat balance components are minimal.

A large $\partial T_{s o}-T_{s i} \partial F$ can be achieved with an optimum power input $(Q)$ to the gauge. For the species in this study this was determined with a series of evaluations at different levels of $Q$ and plotting $T_{s o}-T_{s i}$ vs sap flow (Fig. 3). Although there were no differences in accuracy ( $\leq 10 \%$ ) among the individual evaluations for each species, the largest $\partial T_{s o}-T_{s i} / \partial F$ values were obtained with $Q$ in the range of 0.04 to 0.06 watts. A similar testing procedure identified the optimum $Q$ for soybean seedlings (Senock and Ham 1993). Even though the overall accuracy of sap flow gauges 


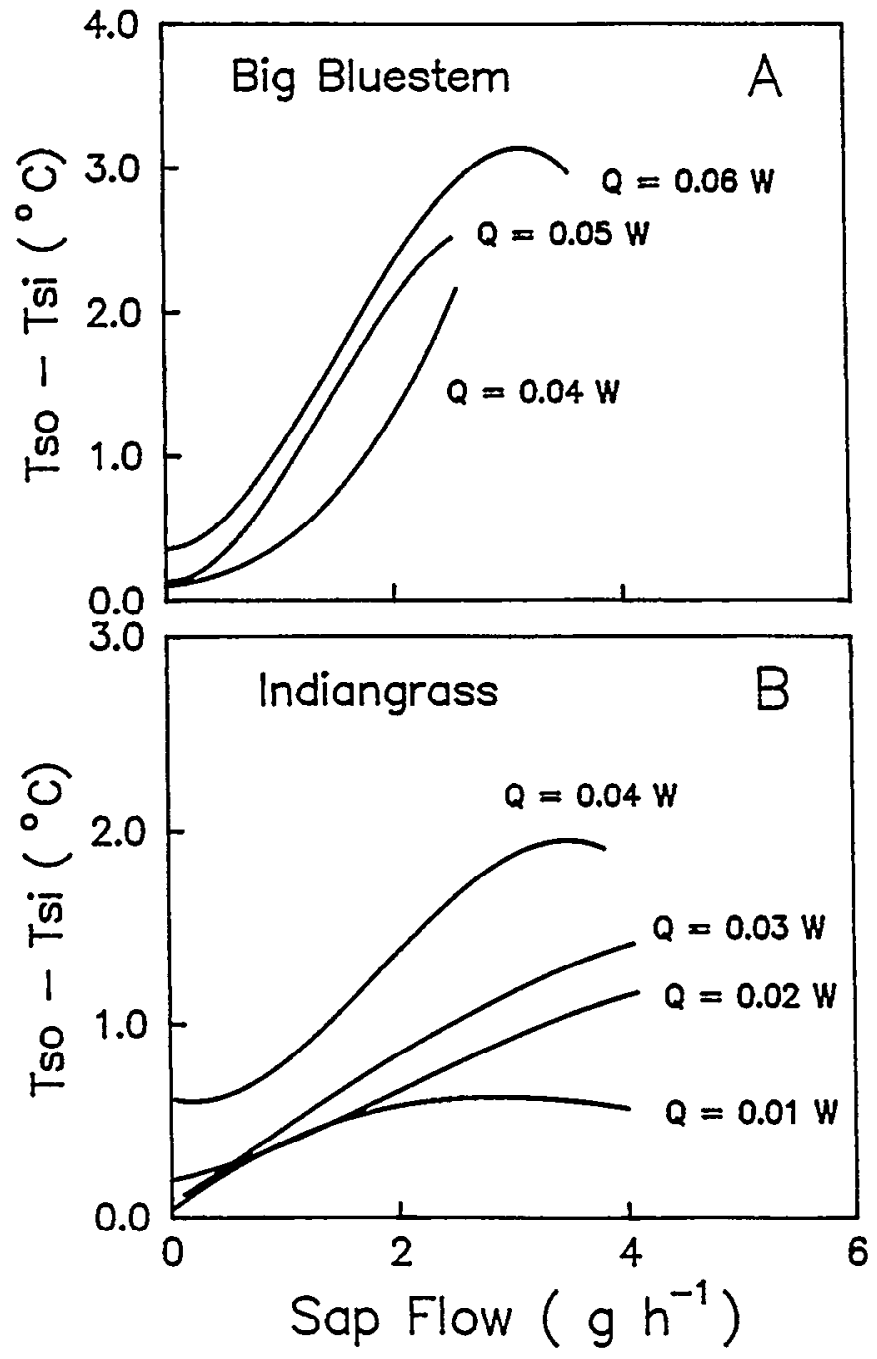

Fig. 3. $T_{s o}-T_{s i}$ in relation to sap flow rate at different input power $(Q)$ levels for big bluestem (A) and indiangrass (B). For all tests, gauge estimates were within $10 \%$ of gravimetric measurements.

at high flow rates is not a function of $Q$ (Ham and Heilman 1990 ), at the low flow rates probably typical of most range grasses, proper selection of $Q$ may avoid any physiological or structural damage to the plant stem while achieving optimum gauge response to sudden changes in sap flow.

The capability of the gauge to respond to sudden changes in sap flow can be quantified with a first-order time constant determined using a step change in flow rate (accomplished by severing the plant stem directly above the gauge) and monitoring the time rate change in computed sap flow. Time constants of 5 to 20 minutes have been reported for herbaceous and tree species with large stems at high flow rates (Baker and van Bavel 1987, Steinberg at al. 1989). Figure 4 shows that when the flow rate was near $3 \mathrm{~g}$ hour ${ }^{-1}$, the gauge time constant for indiangrass was only $19 \mathrm{sec}-$ onds. This value is similar to that found for a soybean seedling (15 seconds) and can be attributed to the small mass of the heated stem segment (Senock and Ham 1993). Furthermore, for a given gauge configuration and plant, the time constant of a sap flow gauge will decrease as flow increases (Kucera et al. 1977). The laboratory tests in this study were conducted with light intensities only approximately $25 \%$ of full sunlight, thus suggesting that a

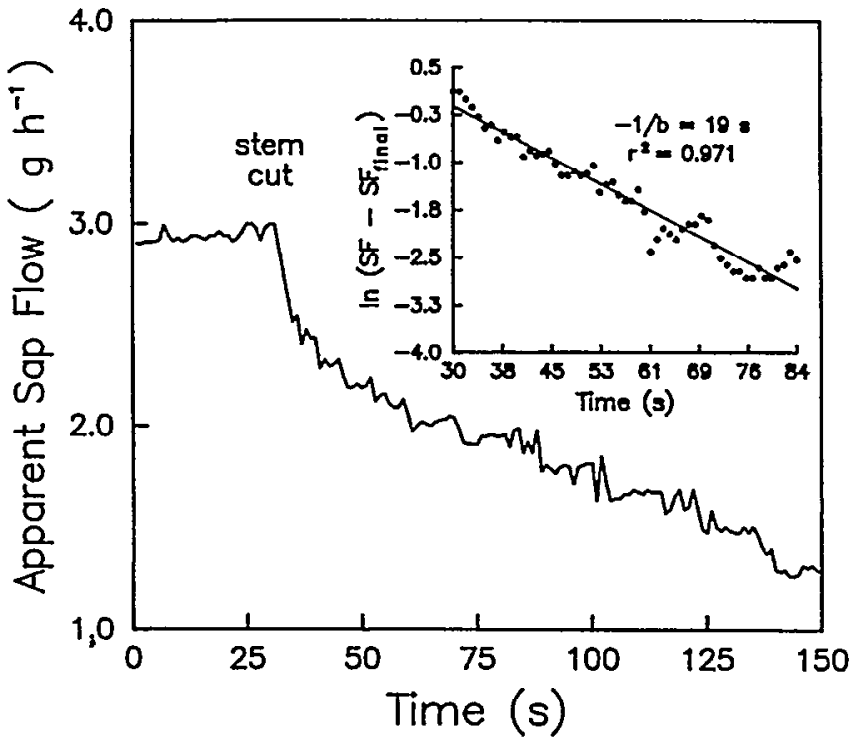

Fig. 4. Change in apparent sap flow rate following stem excision, recorded every $1 \mathrm{~s}$. The inset shows the system time constant derived from the difference between initial (SF) and final (SF final) sap flow rate with the later value being $63 \%$ of the initial rate.

similar or faster response time can be expected under higher light intensities when sap flow rates are higher.

\section{Greenhouse Tests}

Environmental conditions in the greenhouse not only fluctuated in response to normal diurnal variations in solar radiation but there were also rapid changes in air temperature caused by the evaporative cooling system used to regulate interior temperatures (Fig. 5a). Gauge performance tests under these conditions always resulted in computed sap flow being consistently below gravimetric water loss and negative flows were often computed (Fig. 5b). This situation was never observed in any of the laboratory tests. The computed negative flows were not entirely the result of a negative $T_{s o}-T_{s i}$ (Fig. 5c). Additionally, using the thermocouples on the stem surface to measure $S$ (eq. 1) did not significantly change the heat balance or the flow estimates. The negative flows were largely a result of increases in $Q_{r}$ above $Q$ thus forcing a negative residual $Q_{f}$ (Fig. 5c). The explanation for $Q_{r}$ being greater than the total power input into the stem segment has to be presented in terms of the thermodynamics of a heat balance sap flow gauge and the approximate way the component heat fluxes are measured.

The radial heat flow, $Q_{r}$ is the product of the thermopile output (E) and the thermal conductivity of the gauge, $K_{g}$. Regardless of the method used to select $K_{g}$, once chosen it becomes constant for the measurement period under consideration. Fluctuations in $Q_{r}$ then become strictly a function of $E$ which is the temperature differential (DT) between the interior (hot junctions) and exterior (cold junctions) of the cork-neoprene chassis (Fig. 1a). The greater the $D T$ the higher $E$, whereas a lower $D T$ means a lower $E$. Under normal conditions, when sap flow has ceased or is minimal, $D T$ is greatest because convective heat loss is minimal and the higher $E$ results in the highest $Q_{r}$ values. When sap flow is occurring within the plant, heat is removed from the stem segment by convection in the sap stream, which decreases $D T$ and produces a corresponding decrease in $E$, and thus $Q_{r}$. Because the 


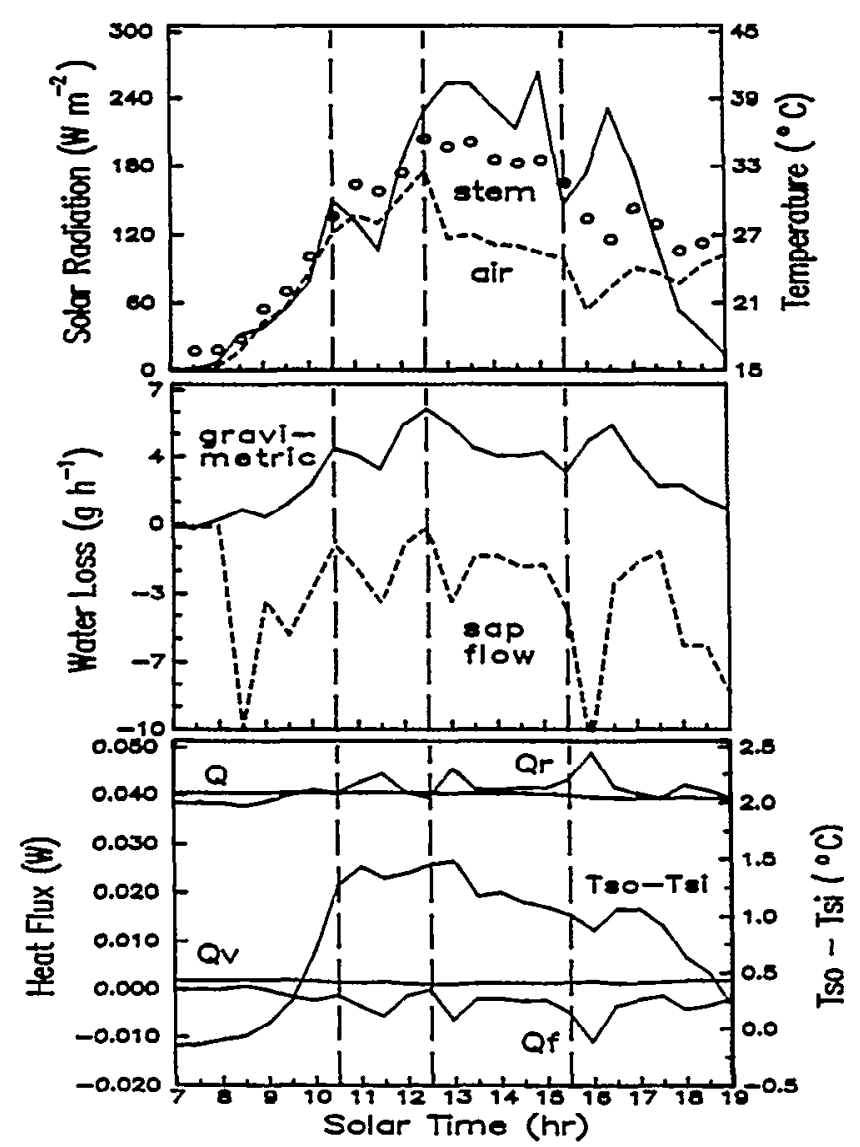

Fig. 5. Representative greenhouse example of the performance of a sap flow gauge on an individual culm of indiangrass: (A) ambient environmental conditions of global solar irradiance and air temperature, and plant stem surface temperature; (B) gauge computed sap flow compared to gravimetric measurements of plant water loss; (C) heat balance components, $Q=$ power input, $Q_{f}=$ convective heat flux, $Q_{r}=$ radial heat flux, $Q_{v}=$ axial heat flux, and $r_{s o^{-}}$ $T_{s i}$. Dotted vertical lines indicate specific times discussed in the text.

energy balance approach is used in calculating sap flow under the assumptions of steady-state conditions and heat energy input to the plant stem is predominately from the gauge heater, $Q_{r}$ should never be greater than $Q$ if $S$ is indeed zero. The fact that this did occur in the greenhouse when gravimetric measurements established that sap flow was occurring indicates that perhaps $Q_{r}$ was not being measured accurately by the thermopile. Accurate measurements of $Q_{r}$ by a thermopile in a single radial plane may be inadequate if spatial variability of thermal gradients exist within the gauge. However, with the assumption that $Q_{r}$ was accurately measured by the thermopile, the remaining explanation for $Q_{r}$ being greater than $Q$ was that the other important assumption of steady-state conditions within the heated stem segment was no longer valid.

The energy dynamics at the specific times indicated in Figure 5 can be used to illustrate how $Q_{r}$ was being influenced by changes in the external environment. Between 1030 hour and 1230 hour, the rapid 2 to $3^{\circ} \mathrm{C}$ decrease in air temperature increased the stemair temperature gradient that resulted in a positive outward heat transfer away from the stem. At 1230 and 1530 hours, the cooling system in the greenhouse again switched on to rapidly decrease air temperature by $6^{\circ} \mathrm{C}$ while stem temperature remained steady.
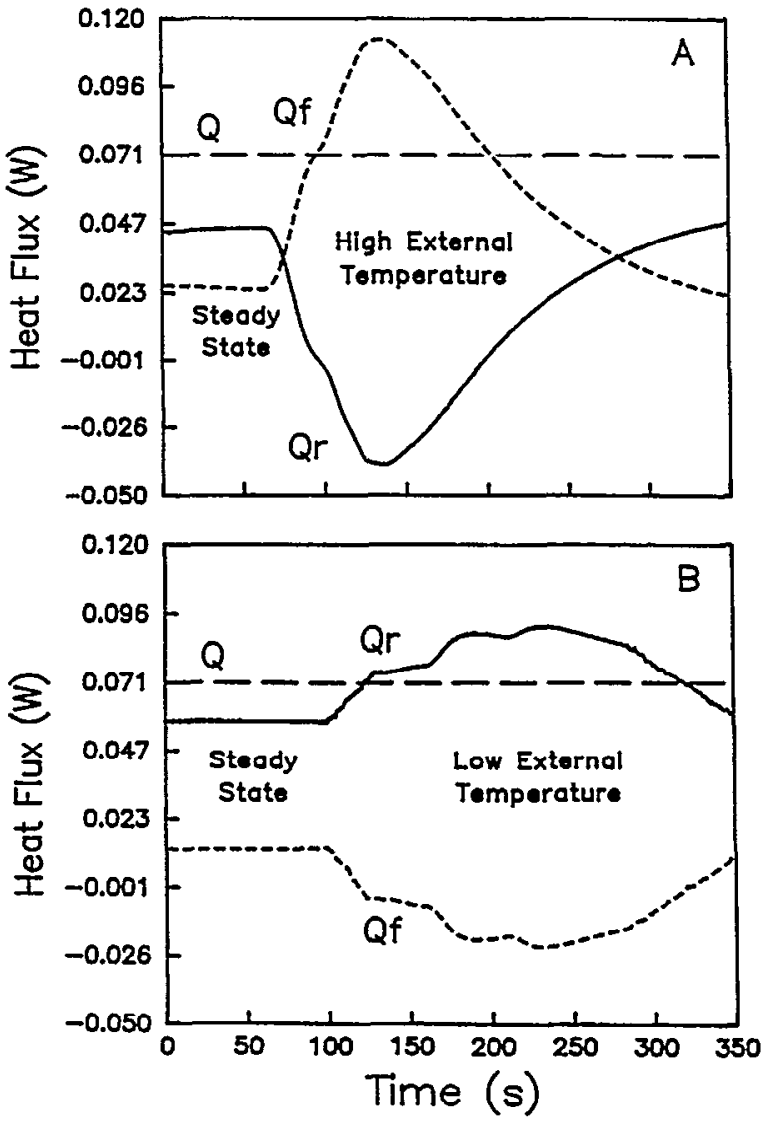

Fig. 6. Effects of sudden changes in steady-state gauge heat balance due to (A) increasing or (B) decreasing gauge insulation surface temperature. Data were collected in the laboratory with a sap flow gauge connected to an artificial flow system with constant water flow ( 4 or $\left.7 \mathrm{~g} \mathrm{~h}^{-1}\right) ; Q=$ power input, $Q_{f}=$ convective heat flux, and $Q_{r}=$ radial heat flux.

In all instances $Q_{r}$ increased with the result being a computed negative flow because of a negative $Q_{r}$. However, $Q_{r}$ also began to decrease once the air temperature became constant (1300 to 1530 hours) or increased (1600 to 1730 hours). The variations in $Q_{r}$ were thus all possibly due to changes in radial heat flux through the gauge insulation caused by sensible heat transfer at the stem-gauge and gauge-air interface. In a series of evaluations with no power input to the gauge, a strong correlation between $Q_{r}$ and the air-stem temperature gradient $(r>0.81)$ also suggested that sensible heat transfer at the gauge-air interface promoted outward radial heat flow. The overall results of the greenhouse tests indicate that $Q_{r}$ in big bluestem and indiangrass with low flows $(<10$ $\mathrm{g}$ hour ${ }^{-1}$ ) is highly sensitive to the external environment.

\section{Radial Heat Flux Analysis}

Although results from the greenhouse tests suggested that sensible heat transfer at the gauge-air interface could effect $Q_{r}$, an independent evaluation of the effect could not be attempted because of the simultaneous changes in sap flow that also occurred in response to fluctuating solar radiation and air temperatures. To circumvent this problem, an artificial flow system was constructed in the laboratory to evaluate gauge responses to the environment while holding $F$ constant. Results showed that changes in external temperature could affect the stem energy bal- 
changes in external temperature could affect the stem energy balance despite the gauge being surrounded with insulation and covered with aluminum foil (Fig. 6). When the insulation surface and foil on the exterior of the gauge was heated from 25 to $73^{\circ} \mathrm{C}$, the steady-state $Q_{r}$ of +0.047 Watt was changed to a -0.040 Watts and the computed flow rate overestimated the known flow rate by $200 \%$ (Fig. 6a). Because $T_{s o}-T_{s i}$ changed by less than $0.5^{\circ} \mathrm{C}$ during the test and $S$ was minimal, the overestimate was due entirely to the change in $Q_{r}$ and subsequent error in the residual $Q_{f}$. Figure $6 \mathrm{~b}$ shows the results for a test when the gauge surface temperature was cooled from 25 to $13^{\circ} \mathrm{C}$ and the steady-state $Q_{r}$ of +0.059 Watts was increased to $+0.093 \mathrm{~W}$. The variation in $T_{s o}-T_{s i}$ during the test was again minimal, as was $S$, and the subsequently computed negative flow rate $\left(-6 \mathrm{~g}\right.$ hour $\left.{ }^{-1}\right)$ was due to the negative $Q_{f}$ residual. Although the data presented in Figure 6 represent extreme examples of changes in temperature, it was apparent from the tests that the rubber foam commonly used to cover sap flow gauges could not completely insulate the gauge or the plant stem from rapidly changing external air temperatures. Additional tests with smaller variations in gauge surface temperature produced the same relative changes in the heat flux components and errors in the computed flow rates.

Changes in air temperature produce a heat energy transfer (q) that can be quantified for the cylindrical system (Incropera and
DeWitt 1990) of a sap flow gauge using the equation

$$
q=\frac{\Delta \mathrm{T}}{R_{\text {cond }}}=\frac{T_{g s .} T_{i}}{\ln \left(r / r_{i}\right) / 2 \pi L k}
$$

where $\Delta \mathrm{T}$ is the temperature gradient $\left({ }^{\circ} \mathrm{C}\right)$ between the plant stem $\left(T_{i}\right)$ and the gauge surface $\left(T_{g s}\right)$, and $R_{\text {cond }}$ is the thermal resistance $(\mathrm{m} \cdot \mathrm{C} / \mathrm{W})$ to conductive heat flow calculated using $r$, the distance to the insulation surface $(9.5 \mathrm{~mm}), r_{i}$ is the radius of the enclosed stem $(2.5 \mathrm{~mm}), \mathrm{L}$ is the heater width $(10 \mathrm{~mm})$ and $\mathrm{k}$, the insulation (AP Armaflex Pipe Insulation, Armstrong World Industries, Lancaster, Penn.) thermal conductivity $(=0.039$ $\mathrm{W} / \mathrm{m} \cdot \mathrm{C}$ ). The assumptions involved with using the equation are steady-state, one-dimensional heat transfer, and negligible convective or radiative heat exchange between the insulation surface and surroundings. Equation 3 shows that $q$ is directly proportional to $\Delta T$ but inversely proportional to $R_{c o n d}$ which, for a given insulation with constant $k$, is largely dependent on $r$, the insulation thickness. Increases in $r$ will thus decrease $q$ and lessen the impact of changing external temperatures on the stem energy balance. If $q$ were to represent the allowable maximum flux that altered $Q_{r}$ such that the final error in computed sap flow, $F$, was $\leq 10 \%$, then $r$ could be evaluated as a function of $\Delta T$. Using the laboratory data $\left(F=5 \mathrm{~g} \mathrm{hour}^{-1}, Q_{r}=0.05\right.$ Watts), $r$ would have to
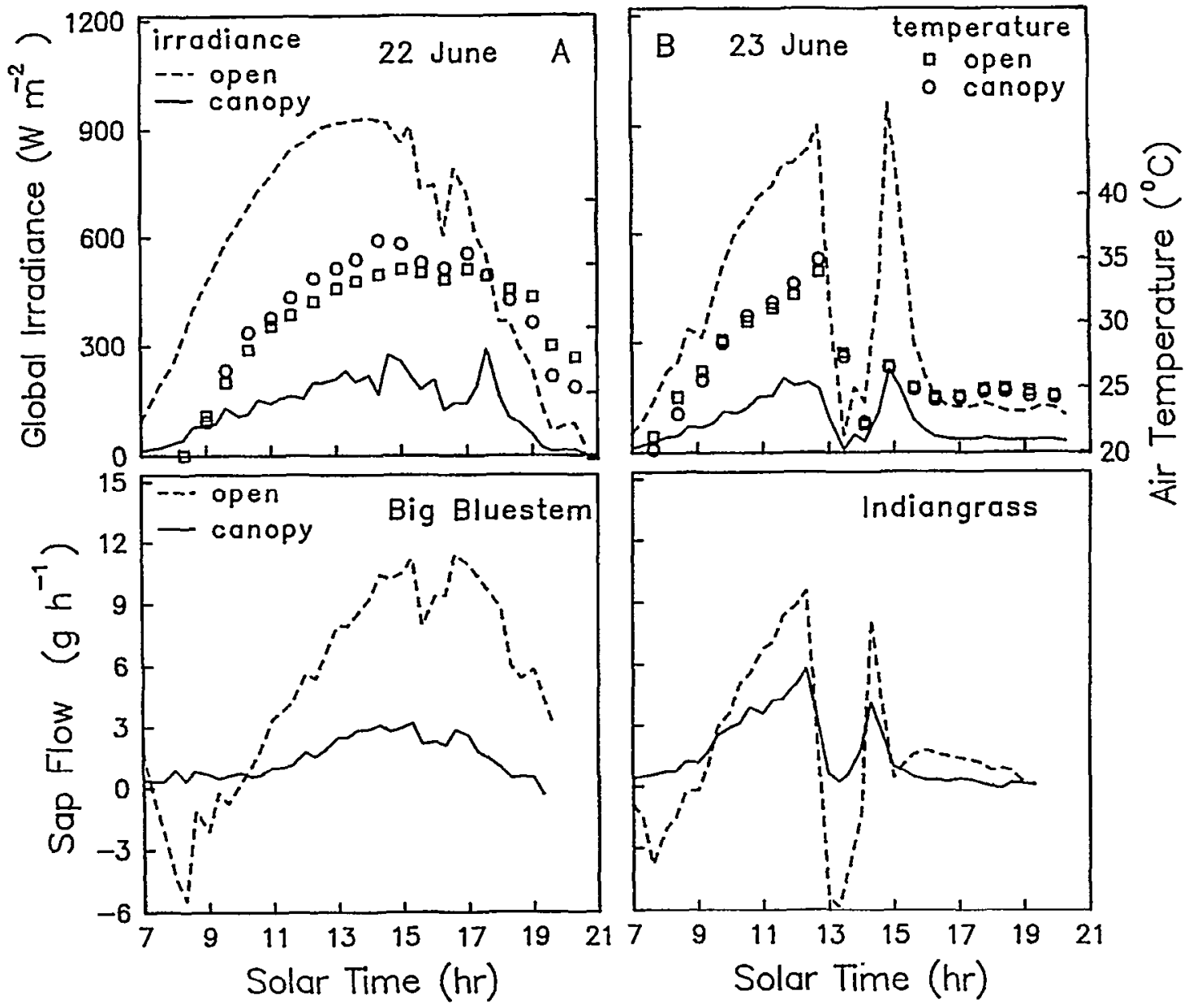

Fig. 7. Representative field examples of global irradiance, air temperature, and sap flow of potted plants of big bluestem (A) and indiangrass (B) placed in the open or within a plant canopy. Sap flow data are from single gauges. 
be sufficient to limit $q$ to $5 \%$ of $Q_{r}$ or \pm 0.003 Watts. Sample calculations with equation 3 showed that at $\Delta T=3^{\circ} \mathrm{C}$, more than $30 \mathrm{~mm}$ of insulation would have to be used to minimize $q$ below 0.003 Watts. However, there is only a small change in the limit of $\Delta T$ to be gained above $21 \mathrm{~mm}$ of insulation. In addition, because the use of a rapid change in $\Delta T$ to calculate $q$ (as compared to a gradual temperature change) produces a conservative estimate of $r$, the optimum insulation thickness would probably range from 20 to $25 \mathrm{~mm}$ when using sap flow gauges on range grasses under conditions of small temperature fluctuations. Equation 3 also shows that to hold $q$ constant, $r$ must be increased exponentially in response to linear increases in $\Delta T$ and sample calculations show that no reasonable amount of insulation could be used to maintain $Q_{r}$ at $0.05 \pm 0.003$ Watts if $\Delta T>3^{\circ} \mathrm{C}$. Although the maximum allowable error in $Q_{r}$ changes as a function of $F$, this simplified approach suggests that large abrupt changes in external temperatures may produce errors in the computed sap flow rates.

\section{Field Tests}

Similar to the laboratory tests, gauge-estimated daily water loss for both species was consistently within $\pm 10 \%$ of gravimetrically measured water loss when the potted plants were placed within the plant canopy (Table 1). However, when both species were placed in the open, the gauges often severely over- or underestimated daily water loss. Examination of the diurnal patterns showed that the early morning estimates of sap flow of plants in the open were often negative (Fig. 7a,b). This suggests that when gauges on plants in the open accurately estimated daily values on June 23 and July 17 (Table 1), results may have been due to compensating periods of errors in computed sap flow. Sap flow for the plants within the shaded canopy, albeit lower, followed the diurnal course of irradiance with no apparent anomalies.

Because $T_{s o}-T_{s i}$ was always positive and generally above 0.5 ${ }^{\circ} \mathrm{C}$, the failure of the gauges to operate properly on plants in the open was due to the same alterations in the heat energy balance as occurred in the greenhouse tests. During the morning hours, $Q_{r}$ alone was greater than $Q$ (data not shown), thus resulting in a negative $Q_{f}$ as the residual heat flux (eq. 2) and consequently, a negative flow rate (Fig. 7a,b). This may have occurred because of a temperature gradient within the $12-\mathrm{mm}$ thick gauge insulation caused by early morning dew that often coated the gauges on plants in the open but not those gauges on plants within the canopy. The latent heat flux caused by dew evaporation would have had a cooling effect on the surrounding insulation and thus altered $Q_{r}$ Data from a day when rapid midday changes in irradiance and air temperature occurred also showed large negative flow rates from gauges on plants in the open but not from those gauges on plants within the canopy (Fig. 7b). In contrast, large midday overestimates of sap flow for gauges on plants in the open were often suspected because of a very low or negative $Q_{r}$ that was possibly due to rapid heating of the gauge surface by solar radiation. Shading of the gauge from solar radiation with some sort of shield may have protected the gauge from the effects of rapid heating, but the only solution to changes in air temperature is to provide additional insulation. The distortions in the heat flux components for the gauges on plants in the open confirmed that rapid changes in the external environment will significantly affect the accuracy of sap flow measurements for range grasses, and that gauge insulation thickness will have to be maximized to protect against rapid heating or cooling of the gauge under field
Table 1. Daily water use of potted plants placed in the open or within a plant canopy determined by gravimetric measurement and cumulative sap flow estimates. Sap flow data are measurements from single gauges.

\begin{tabular}{lllccc}
\hline \hline Date & Treatment & Species & \multicolumn{2}{c}{ Gravimetric Sap flow } & Difference \\
\hline \multirow{2}{*}{$6-22$} & & & $-\ldots$ (g day) $-\cdots$ & $(\%)$ \\
& open & bluestem & 80.6 & 62.7 & -22.2 \\
& open & indiangrass & 48.2 & 35.6 & -26.1 \\
& canopy & bluestem & 19.7 & 20.5 & +4.1 \\
& canopy & indiangrass & 45.9 & 47.5 & +3.5 \\
$6-23$ & open & bluestem & 36.7 & 35.6 & -3.0 \\
& open & indiangrass & 47.7 & 62.3 & +30.6 \\
& canopy & bluestem & 23.8 & 21.9 & -8.1 \\
& canopy & indiangrass & 24.3 & 26.7 & +10.0 \\
$7-13$ & open & bluestem & 46.4 & 96.5 & +108.0 \\
& open & indiangrass & 59.7 & 74.2 & +24.3 \\
& carlopy & bluestem & 36.1 & 34.7 & -3.9 \\
& canopy & indiangrass & 25.3 & 27.0 & +6.7 \\
$7-17$ & open & bluestem & 93.3 & 64.4 & -31.8 \\
& open & indiangrass & 53.6 & 49.2 & -8.2 \\
& canopy & bluestem & 29.9 & 32.5 & +8.7 \\
& canopy & indiangrass & 31.4 & 28.7 & +8.6 \\
\hline
\end{tabular}

conditions.

\section{Implications for Rangeland Research}

The dynamics of the gauge response and the consistent accuracy in the laboratory indicates the potential of heat balance sap flow gauges for directly measuring water use of range grasses. The greenhouse tests and some field tests, however, illustrated that limitations may also exist to using sap flow gauges to measure the low flow rates of grasses if the external environment is fluctuating rapidly. Accurate water use estimates obtained from the gauges placed within the protection of the oat canopy indicated that reliable measurements of sap flow for range grasses can be obtained in certain field situations.

The sap flow gauges used in this study have been successfully employed and validated under field conditions on several tallgrass prairie species (Ham et al., unpublished data). Although the tallgrass prairie may provide unusually high vegetative canopy cover in comparison to other rangeland ecosystems, the minimal amount of cover necessary to provide adequate gauge protection has yet to be determined. If the gauges are placed on the grass tiller directly above the soil surface and surrounding plant canopy is available to provide some protection from direct exposure to solar irradiance and other environmental factors, then accurate measures of range grass water use can be expected. It is also plausible that the interior of widely spaced bunchgrass species may provide enough protection to allow sap flow gauges to be successfully used in the field. Protection of heat balance sap flow gauges from extreme ambient conditions provided by a vegetative canopy appears to be important for any plant species (Gutierrez et al. 1994).

Regardless of the field situation or the species investigated, a critical evaluation of the effect of ambient conditions on gauge performance should be done to insure reliable plant water use estimates (Shackel et al. 1992). Examination of the heat flux components would allow the researcher to make an objective decision as to the validity of the gauge performance. The objectivity would come from understanding the stem energy balance 
approach and fully considering the sap flow equation. Periods of computed negative flows because of a negative $Q_{f}$ or $T_{s o}-T_{s i}$ should alert the researcher to problems in the data (Shackel et al. 1992, Gutierrez et al. 1994). Experience gained from preliminary laboratory or greenhouse validation tests on the species of interest may also provide a reference point for deciding if the computed flows in a field setting were reasonable or should be suspect (Cohen et al. 1993). Similarly, comparison of computed sap flows with water loss estimates obtained from other field based methods (lysimeters, Bowen ratio-energy balance) may confirm or contradict the flow measurements (Gerdes et al. 1994). Like all other plant physiological measurement techniques a thorough examination of all relevant factors is necessary for any meaningful information to be extracted from data collected with modern instrumentation (Bloom 1991).

In comparison to many other methods, sap flow gauges can provide direct and non-invasive measurements of plant water use. Perhaps most important, the technique provides continuous data on the flow of water within the plant stem. Although 20-30 minute average values were used in this study, the rapid time constant would allow for even shorter time periods of average sap flow to be calculated. Because grasses have limited internal plant water capacitance (Nobel and Jordan 1983), water use by range grasses as measured with sap flow gauges is nearly equivalent to transpiration and could be related directly to various environmental factors (net radiation, air saturation deficit, temperature, and wind speed) that influence plant water use. Sap flow can be summed easily over time for determining the total amount of water used by individual species in different treatments (Steinberg et al. 1991, Gavloski et al. 1992). In breeding and selection programs, cumulative sap flow could provide an quantitative measure of water use over the life of a grass plant that is not feasible with instantaneous measures of stomatal conductance or transpiration (Johnson and Asay 1993). Regardless of application, the previous reports of sap flow measurements on honey mesquite in the field (Dugas and Mayeux 1991, Dugas et al. 1992) and the results on range grasses presented here are establishing the use of heat balance sap flow gauges as a viable method of measuring range-plant water use.

\section{Literature Cited}

Ansley, R.J., P.W. Jacoby, and R. Hicks. 1991. Leaf and whole plant transpiration in honey mesquite following severing of lateral roots. J. Range Manage. 44:577-582.

Baker, J.M., and J.L. Nieber. 1989. An analysis of the steady-state heat balance method for measuring sap flow in plants. Ag. For. Meteorol. 48:93109.

Baker, J.M., and C.H.M. Van Bavel. 1987. Measurement of mass flow of water in the stems of herbaceous plants. Plant, Cell, Environ. 10:777-782.

Bloom, A.J. 1991. Principals of instrumentation for physiological ecology, pp. 1-14. In: R.W. Pearcy, J. Ehleringer, H.A. Mooney and P.W. Rundel (eds.), Plant physiological ecology: field methods and instrumentation. Chapman and Hall, New York, N.Y.

Brown, R.W. 1977. Water relations of range plants, p. 97-140. In: R.E. Sosebee (ed.), Rangeland plant physiology. Soc. Range. Manage., Denver, Colo.

Cohen, Y., S. Takeuchi, J. Nozaka, and T. Yano. 1993. Accuracy of sap flow measurement using heat balance and heat pulse methods. Agron. J. 85:1080-1086.

Dugas, W.A. 1990. Comparative measurement of stem flow and transpiration in cotton. Theor. Appl. Climatol. 42:215-221.

Dugas, W.A., and H.S. Mayeux. 1991. Evaporation from rangeland with and without honey mesquite. J. Range Manage. 44:161-170.
Dugas, W.A., M.L. Heuer, and H.S. Mayeux. 1992. Diumal measurements of honey mesquite transpiration using stem flow gauges. J. Range Manage. 45:99-102.

Fichtner, K., and E.D. Schulze. 1990. Xylem water flow in tropical vines as measured by a steady state heating method. Oecologia $82: 355-361$.

Gavloski, J.E., G.H. Whitfield, and C.R. Ellis. 1992. Effect of restricted watering on sap flow and growth in corn. Can. J. Plant Sci. 72:361-368.

Gerdes, G., B.E. Allison, and L.S. Pereira. 1994. Overestimation of soybean crop transpiration by sap flow measurements under field conditions in central Portugal. Irrig. Sci. 14:135-139.

Gould, F.W., and R.B. Shaw. 1983. Grass systematics. Texas A\&M University Press, College Station, Tex

Griffin, R.C., and B.A. McCarl. 1989. Brushland management for increased water yield in Texas. Water Resources Bull. 25:175-186.

Groot, A., and K.M. King. 1992. Measurement of sap flow by the heat balance method: numerical analysis and application to coniferous seedlings. Agr. For. Meteorol. 59:289-308.

Gutierrez, M.V., R.A. Harrington, F.C. Meinzer, and J.H. Fownes. 1994. The effect of environmentally induced stem temperature gradients on transpiration estimates from the heat balance method in two tropical woody species. Tree Physiol. 14:179-190.

Ham, J.M., and J.L. Heilman. 1990. Dynamics of a heat balance stem flow gauge during high flow. Agron. J. 82:147-152.

Ham, J.M., and J.L. Heilman. 1991. Aerodynamic and surface resistances affecting energy transport in a sparse crop. Agr. For. Meteorol. 53:267-284.

Incropera, F.P., and D.P. DeWitt. 1990. Fundamentals of heat and mass transfer, pp. 80-119. 3rd ed. John Wiley \& Sons, New York, N.Y.

Johnson, D.A., and K.H. Asay. 1993. Viewpoint: selection for improved drought response in cool-season grasses. J. Range Manage. 46:194-202.

Kucera, J., J. Cermak, and M. Penka. 1977. Improved thermal method of continually recording the transpiration flow rate dynamics. Biol. Plant. 19:413-420.

Massman, W.J. 1992. A surface energy balance method for partitioning evapotranspiration data into plant and soil components for a surface with partial canopy cover. Water Resources Res. 28:1723-1732.

Nobel, P.S., and P.W. Jordan. 1983. Transpiration stream of desert species: resistances and capacitances for a $\mathrm{C}_{3}, \mathrm{C}_{4}$, and CAM plant. J. Exp. Bot. 34:1379-1391.

Parton, W.J., W.K. Lauenroth, and F.M. Smith. 1981. Water loss from a shortgrass steppe. Agr. For. Meterol. 24:97-109.

Sakuratani, T. 1979. Apparent thermal conductivity of rice stems in relation to transpiration stream. Jap. Agr. Meteorol. 34:177-187.

Sakuratani, T. 1981. A heat balance method for measuring water flux in the stem of intact plants. Jap. Agr. Meteorol. 37:9-17.

Sakuratani, T. 1984. Improvement of the probe for measuring water flow rate in intact plants with the stem heat balance method. Jap. Agr. Meteorol. 40:273-277.

Sakuratani, T. 1987. Studies on evaporation from crops. II. Separate estimation of transpiration and evaporation from a soybean field without water storage. Jap. Agr. Meteorol. 42:309-317.

Sakuratani, T. 1990. Measurement of the sap flow rate in stem of rice plant. Jap. Agr. Meteorol. 45:277-280.

Senock, R.S., and J.M. Ham. 1993. Heat balance sap flow gauge for small diameter stems. Plant, Cell, Environ. 16:593-601.

Shackel, K.A., R.S. Johnson, C.K. Medawer, and C.J. Phene. 1992. Substantial crrors in cstimates of sap flow using the heat balance technique on woody stems under field conditions. J. Amer. Soc. Hort. Sci. 117:351356.

Stannard, D.I. 1993. Comparison of Penman-Monteith, ShuttleworthWallace, and modified Priestly-Taylor evapotranspiration models for wildland vegetation in semi-arid rangeland. Water Resources Res. 29:13791392.

Steinberg, S., C.H.M. van Bavel, and M.J. McFarland. 1989. A gauge to measure mass flow rate of sap in stems and trunks of woody plants. J. Amer. Soc. Hort. Sci. 114:466-472.

Steinberg, S., J.M. Zajicek, and M.J. McFarland. 1991. Short-term effect of uniconazole on the vater relations and growth of Ligustrum. J. Amer. Soc. Hort. Sci. 116:460-464.

van Bavel, C.H.M. 1991. Radial and vertical heat conduction in stem and trunk flow gauges. Hort. Sci. 26:73.

Wight, J.R., and C.L. Hanson. 1990. Crop coefficients for rangeland. J. Range Manage. 43:482-485. 